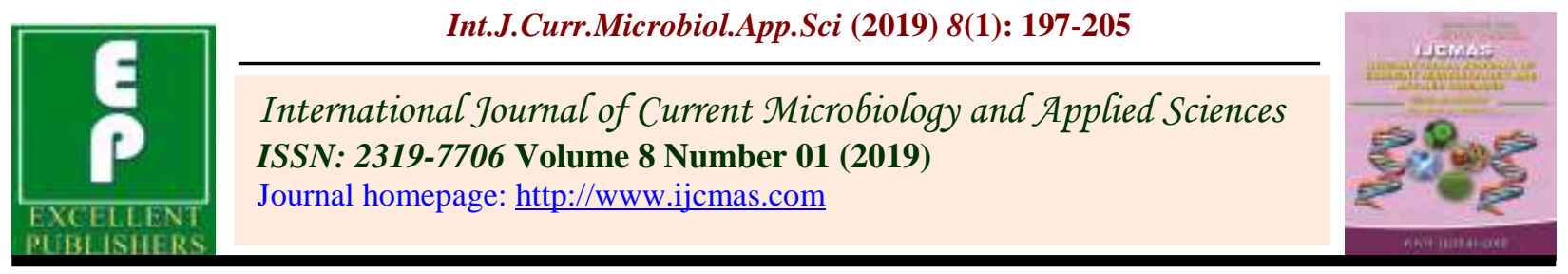

Original Research Article

https://doi.org/10.20546/ijcmas.2019.801.021

\title{
Design and Development of Oscillating Intercultural Equipment for Rice
}

\author{
D. Anil Kumar ${ }^{1 *}$, S. Joseph Reddy², B. Sanjeeva Reddy ${ }^{3,4}$, \\ L. Edukondalu ${ }^{1}$ and V. Srineevasa Rao ${ }^{5}$ \\ ${ }^{1}$ NTR College of Agricultural Engineering, ANGRAU, Bapatla- 522 101, India \\ ${ }^{2}$ Regional Agricultural Research Station, Nandyal - 518 502, India \\ ${ }^{3}$ ICAR - Central Research Institute for Dryland Agriculture, Hyderabad - 500 059, India \\ ${ }^{4}$ Institute of Agricultural Engineering \& Technology, PJTSAU, Hyderabad-500 030, India \\ ${ }^{5}$ Agricultural College, ANGRAU, BAPATLA - 522 101, India \\ *Corresponding author
}

\begin{tabular}{|c|c|}
\hline & A B S T R A C T \\
\hline Keywords & \multirow{4}{*}{$\begin{array}{l}\text { Transplanting is the major method of rice cultivation in India. Irrespective of the method } \\
\text { of paddy crop establishment, weed is a major impediment to rice production through its } \\
\text { ability to compete for resources and their impact on paddy crop yields. The cutting tool } \\
\text { will make a reciprocation maximum motion of } 6 \mathrm{~cm} \text { perpendicular to the direction of } \\
\text { transplanted crop rows. This gives an effective working width of } 16 \mathrm{~cm} \text { leaving } 7 \mathrm{~cm} \text { as } \\
\text { root protective zone on either side of the weeded rows. The required stroke lengths } \\
\text { selected for the weeding tool } 60,40 \text { and } 20 \mathrm{~mm} \text {, could be obtained at crank radius of } 30 \text {, } \\
20 \text { and } 10 \mathrm{~mm} \text {, respectively. The linear speeds of sliding bar for } 20,40 \text { and } 60 \mathrm{~mm} \text { stroke } \\
\text { lengths were observed to be } 0.25,0.51 \text { and } 0.76 \mathrm{~m} \mathrm{~s}^{-1} \text {, respectively. The peripheral and } \\
\text { angular velocity of crank wheel were } 4.97 \mathrm{~m} \mathrm{~s}^{-1} \text { and } 39.77 \mathrm{rad} \mathrm{s}^{-1} \text {, respectively. The force } \\
\text { required to operate the slider bar in the mechanism was } 2202.8 \mathrm{~N} \text {, whereas the force } \\
\text { exerted by the crank wheel to the sliding bar was } 2738.08 \mathrm{~N} \text {. Hence, the design was } \\
\text { satisfactory. }\end{array}$} \\
\hline $\begin{array}{l}\text { Design and } \\
\text { Development } \\
\text { Oscillating } \\
\text { Intercultural } \\
\text { Equipment }\end{array}$ & \\
\hline Article Info & \\
\hline & \\
\hline
\end{tabular}

\section{Introduction}

Rice (Oryza sativa L.) is India's prominent crop, and is the staple food for most of the Indians. India has the world's largest area under rice cultivation and is one of the largest producers of white rice, accounting for 20 per cent of global production. The rice production in India in 2017-18 is 163.516 MT from 43.5 Mha area under rice cultivation (Anonymous,
2018). The proportion of people working in agricultural sector has decreased and the consumption demands have increased gradually. The performance of agricultural affairs must be improved to have higher efficiency (Kurstjens, 2007). Transplanting is the major method of rice cultivation in India. Irrespective of the method of paddy crop establishment, weed is a major impediment to rice production through its ability to compete 
for resources and their impact on paddy crop yields. Under extreme conditions, weeds are responsible for high yield losses, to the extent of complete crop loss. Out of the losses due to various biotic stresses, weeds are known to account for nearly one third of yield reduction (Singh et al., 2005; Savary et al., 2005; Rao and Nagamani, 2007). Thus, weed control is a major prerequisite for improved rice productivity and production. Weeds not only cause huge reductions in rice yields, but also increase cost of cultivation, reduces input use efficiency, interfere with other production operations, impairing quality, act as alternate hosts for several insect pests, diseases, affect esthetic look of the ecosystem as well as native biodiversity and affect human and livestock health (Rao, 2011).

Effective prevention and control of rice field weeds is of great significance for improving rice yield. In recent years, with the expansion of the production scale of organic rice, there is an urgent need for an effective physical weeding control method for rice fields.

Line sowing method of paddy cultivation with tractor drawn seed-cum-ferti drills or transplanting of raised paddy nursery in rows is becoming a common practice in Andhra Pradesh due to promotion of appropriate package of machines for paddy cultivation through state department of Agriculture. Research work was under taken on selfpropelled intercultural equipment in paddy by many researchers in USA, Korea, and Japan and in other countries. In India, though research was undertaken on manually operated cone-weeders and power operated selfpropelled weeders, no research work was reported on tractor operated intercultural equipment especially in wet land. Keeping these points in view, a research on design and development of oscillating weeding machine for rice was taken up with the following objectives.

\section{Machine design considerations}

\section{Weeding tool design considerations}

To develop the weeding tool an effective width of $10 \mathrm{~cm}$ and the maximum working stroke of $6 \mathrm{~cm}$ in design was considered. To obtain the effective kneading of the wet soil to uproot the weeds, to the tool base 4 spikes will be provided at an effective distance of $2.5 \mathrm{~cm}$ centre to centre distance of each spike and two chain links on extreme edges to bury the uprooted weeds. The cutting tool will make a reciprocation maximum motion of $6 \mathrm{~cm}$ perpendicular to the direction of transplanted crop rows. This gives an effective working width of $16 \mathrm{~cm}$ leaving $7 \mathrm{~cm}$ as root protective zone on either side of the weeded rows. Since, obtaining oscillation on both on right and left side from the central position of the tool is a difficult proposition; it was decided to fix the tool at the edge of the root protective zone of a crop row and tool makes reciprocation motion in the lateral direction. Since, a low horse power tractor was selected as a power source, to cover more area in a unit time and utilize maximum power six similar tools will be fitted to the main frame of the machine. Based on these considerations the power requirement for weeding operation, torque required for the connecting rod and crank arm etc. were calculated.

\section{Machine description}

The weeding machine basically consists of a single bar frame with hitch mast, a crank wheel to provide reciprocate motion, power transmission system from PTO to the crank wheel and weeding tools attached to reciprocating arm. The single bar frame provides appropriate support and base to fit the crank wheel and a reciprocating bar. The rotary power transmission is provided from PTO to the crank wheel using universal shaft and a fixed straight shaft rotating with the support of two pedestal bearings. The crank 
wheel is directly fixed to the straight shaft. The crank wheel in turn is connected to the reciprocating bar through a connecting rod to convert rotary motion into reciprocating motion. The weeding tool tynes are fixed to the reciprocating bar at set centre to centre distance to obtain reciprocating motion to disturb the soil to a depth of $5 \mathrm{~cm}$ and uproot the weeds in operation.

\section{Stroke length in slider crank mechanism}

The slider-crank mechanism is used to convert rotary motion to a reciprocating motion or vice versa. In the Figure 1, a slider-crank mechanism was shown and the parameters that used to define the angles and the link lengths were presented. As in the case of four-bar mechanism, the extended and folded dead centre positions, the crank and the coupler are collinear (coupler link is commonly called connecting rod in slider-crank mechanisms). Full rotation of the crank is possible if the eccentricity (C) is less than the difference between the connecting rod $\left(l_{\mathrm{c}}\right)$ and the crank length (crank radius ' $r$ ) and the crank length is less than the connecting rod length (e.g. $\mathrm{C}<\left(l_{\mathrm{c}^{-}}\right.$ r) and $l_{\mathrm{c}}>\mathrm{r}$ )

Using the principal of right angled triangles formed at the dead centre positions

$$
S_{e}=\left[\left(r+l_{c}\right)^{2}-C^{2}\right]^{\frac{1}{2}}
$$

Similarly, $\quad S_{f}=\left[\left(r-l_{c}\right)^{2}-C^{2}\right]^{\frac{1}{2}}$

Where, $\mathrm{S}_{\mathrm{e}}=$ Horizontal distance between crank centre to dead centre in fully extended position of the slider, mm

$\mathrm{S}_{\mathrm{f}}=$ Horizontal distance between crank centre to dead centre in fully folded position of the slider, $\mathrm{mm}$

$\mathrm{C}=$ Clearance between centre line of oscillating shaft and centre of crank wheel, $\mathrm{mm}$
Length of stroke $(S), m m=S_{e}-S_{f}$

Length of stroke $=$ Distance of slider travel between dead centers

If the eccentricity ' $\mathrm{C}$ ' is zero $(\mathrm{C}=0)$ the slider crank mechanism is called an in-line slider crank and the stroke is twice the crank length $(\mathrm{S}=2 \mathrm{r})$. If the eccentricity ' $\mathrm{C}$ ' is not zero $(C \neq 0)$, it is usually called an offset slider crank mechanism. For the present study, an offset slider crank mechanism was considered. Geometry representation of slider crank mechanism was shown in Figure 1.

The speed of oscillation is calculated using an equation suggested by Celik (2006) as,

Speed of oscillation, $\mathrm{m} \mathrm{s}^{-1}=(\mathrm{S} \times \mathrm{N}) / 30$

Where, $\mathrm{S}=$ length of stroke, $\mathrm{m}$

$\mathrm{N}=$ crank speed, rpm

The velocity of the crank wheel can be calculated by using equation suggested by Sharma and Mukesh (2013).

$$
v, m s^{-1}=\frac{\pi D N}{60}
$$

Where, $\mathrm{D}=$ Diameter of the crank wheel, $\mathrm{m}$ $\mathrm{N}=\mathrm{RPM}$ of the crank wheel

\section{Torque and force delivered to oscillating bar}

The requirement of torque and force to operate the slider crank mechanism is important in design of weeding machine and selection of power source. The slider crank mechanism consists mainly three parts, namely, crank wheel, connecting rod and oscillating bar (i.e. slider). To arrive at the torque and force requirement, the weights of individual components were measured and taken into consideration. The torque and force delivered to oscillating bar by crank wheel was calculated using equations suggested by Ogunlowo and Olaoye (2017). 


$$
T_{S C}=\frac{P_{S C} \times 60}{2 \pi N_{S C}}
$$

Where, $\mathrm{T}_{\mathrm{sc}}=$ Torque delivered by the crank wheel, N-m

$\mathrm{P}_{\mathrm{sc}}=$ Power delivered to the crank wheel, HP

$\mathrm{N}_{\mathrm{sc}}=$ Speed of the crank wheel, RPM

$$
F=F_{C}+F_{S}
$$

$F_{S}=\mu F_{N}$

$F_{N}=m_{t} g$

Where, $\mathrm{F}_{\mathrm{s}}=$ Static force, $\mathrm{N}$

$\mathrm{F}_{\mathrm{C}}=$ Total force coming on to the weeding tools due soil cutting, $\mathrm{N}$

$\mathrm{F}_{\mathrm{N}}=$ Normal force, $\mathrm{N}$

$\mathrm{m}_{\mathrm{t}}=$ Total mass, the oscillating bar and working tools, $\mathrm{kg}$

$\mathrm{g}=$ Acceleration due to gravity, $9.81 \mathrm{~m} \mathrm{~s}^{-2}$

$\mu=$ coefficient of static friction, 0.74 for steel on steel

\section{Materials and Methods}

The machine mainly consisted of the following components, main frame with three point hitch system, slider crank mechanism (crank wheel, connecting rod and oscillating shaft), working tools and chain links.

\section{Main frame with three point hitch system}

A $22 \mathrm{HP} 4 \mathrm{WD}$ tractor was used as power source to operate the intercultural equipment in rice field. The main frame of the machine was fabricated as a single bar frame using a $75 X 65 \mathrm{~mm}$ size M S U- channel having a thickness of $7 \mathrm{~mm}$. The frame length was $2500 \mathrm{~mm}$ to support the slider and crank mechanism. Main frame was provided a three point hitch mast on the flat side of the channel. Three point hitch mast was fabricated using a $65 \mathrm{~mm}$ width mild steel flat with $10 \mathrm{~mm}$ thickness and fitted to two $U$ channel pieces (5 $\mathrm{mm}$ thickness, $40 \mathrm{~mm}$ width and $75 \mathrm{~mm}$ height)provided as an extension bar from the main frame. These two extended channel pieces were connected together using another cross channel material piece to give enough support for the frame and the hitch mast.

\section{Slider crank mechanism}

Slider crank mechanism was designed to convert rotary motion to reciprocating motion. The rotary motion of the PTO shaft transmitted to the slider crank mechanism through the universal joint and a shaft. Slider crank mechanism consists of crank wheel, connecting rod and oscillating shaft. Fabrication details of each component in slider crank mechanism were explained in detailed below.

\section{Oscillating bar}

The length of oscillating bar was fabricated based on the row to row spacing of rice crop. In general, row to row spacing in paddy ranges from 25 to $30 \mathrm{~cm}$. For design calculation in the present case, weeding operation in six rows simultaneously was considered and the length of reciprocating bar was kept as $230 \mathrm{~cm}$.

Two $50 \times 50 \times 6 \mathrm{~mm}$ size of L-angle bars were taken and jointed using weld joints to make a hollow square bar to use as a oscillating bar. It is in a square shape, and fits into the U-shaped main frame. Two roller bearings were fitted inside the L-angle square bar on either side at a center to center distance of $1800 \mathrm{~mm}$. The bearings works smoothly just like a solid metal rollers in the U-channel in which the bar moves sideways from left to right or vice versa. Oscillating bar gets the motion from crank wheel through connecting rod (Fig. 2).

\section{Crank shaft and crank wheel}

A720 mm length and $37 \mathrm{~mm}$ diameter mild steel solid rod was taken and turned to $35 \mathrm{~mm}$ 
diameter and both ends faces were finished. At one end of the finished shaft, splines were cut just like the PTO shaft splines and at another end $60 \times 3 \mathrm{~mm}$ key way groove was made. The shaft thus prepared was fitted on the main frame with the help of two support bars using pedestal bearings of $35 \mathrm{~mm}$ size to give free rotation to the shaft.

A metal plate of $10 \mathrm{~mm}$ thickness was taken and $270 \mathrm{~mm}$ circular flange piece was separated using a gas cutter and the cut piece was smoothly turned to a diameter of 250 mm.A mild steel solid rod of 50x55 mm was taken and turned to smooth surface on the periphery and a $35 \mathrm{~mm}$ bore was drilled.

\section{Connecting rod}

A rectangular solid cross-section $25 \times 25 \mathrm{~mm}$ size rod was used as a connecting rod. One end of connecting rod was positioned at certain position on crank wheel slot and other end is connected to the oscillating shaft using a. The position of connecting rod on crank wheel will decide the stroke length.

\section{Tynes}

As the bar oscillates correspondingly the tools also oscillates disturbing the soil which in turn aid in disturbing and uprooting the weeds from the soil. The length of the tyne required to the tool will be varied according to the ground clearance of the tractor and sinkage of the tyres depending upon the field conditions. A $100 \mathrm{~mm}$ length, 40x4 mm size mild steel Langle pieces were taken and $10 \mathrm{~mm}$ diameter holes two in number were drilled keeping 60 $\mathrm{mm}$ hole to hole center distance by matching two pieces together. The matched pair of cut pieces was welded on outer side of oscillating bar keeping face to face at $26 \mathrm{~mm}$ apart. These welded L-angle pieces work as a brackets to help in fixing the working tool tynes. To adjust the length of tynes $10 \mathrm{~mm}$ diameter holes were drilled over a length of $240 \mathrm{~mm}$ keeping center to center distance $60 \mathrm{~mm}$ apart. Six pieces of $100 \mathrm{~mm}$ length and $18 \times 18 \mathrm{~mm}$ size solid metal pieces were taken and four numbers of spikes of $50 \mathrm{~mm}$ length and 10x10 $\mathrm{mm}$ size were welded at one face to work as a soil disturbing tool. These tools were fitted to the lower end of the tyne using nu and bolt keeping upright down the metal spikes.

\section{Chain links}

While in weed removal practice under wet land conditions it is impossible to visualize weather all weeds are physically removed or not. So, it is a common practice to trample the weed biomass to bury into the soil. So, to achieve the same objective chain links two in number were attached to the tool. When the tool oscillates in between the crop rows chain links will move in a zig-zag path dragging the disturbed soil to cover the weed biomass. Three different lengths (50, 100 and $150 \mathrm{~mm}$ ) and thicknesses( 3,5 and $7 \mathrm{~mm}$ ) chain links were selected for the study and used in the field condition.

\section{Results and Discussion}

To obtain the desired oscillation motion for the working tool, the stroke length of oscillating bar needs to be calculated. The stroke length will depend on the length of connecting rod and the crank wheel slider bar. The required stroke lengths can be achieved by changing the position of connecting rod (i.e. crank radius) on the crank wheel slot. The tyne has to make an oscillatory maximum motion of $60 \mathrm{~mm}$ perpendicular to the direction of travel. As a result the weeding tool will get an effective working width of 160 $\mathrm{mm}$ leaving $70 \mathrm{~mm}$ as root protective zone on either side of the weeded rows. Accordingly, different crank wheel radius positions were selected for a fixed connecting rod length of $700 \mathrm{~mm}$ and stroke lengths were calculated 
without changing the eccentricity value (Table $1)$.

It was observed that the crank position and moment and the stroke length were linearly related with a constant multiplication factor $(\mathrm{S}=2 \mathrm{r})$. The data presented in Figure 3 indicates that without changing the connecting rod and eccentricity values one can obtain the required stroke lengths for the oscillating tool, if the boundary conditions are set within the required limits the required stroke lengths selected for the weeding tool 60,40 and 20 $\mathrm{mm}$, could be obtained at crank radius of 30 , 20 and $10 \mathrm{~mm}$, respectively. This fact was also verified by constraining the crank arm to these limits in the machine and the stroke lengths were found very well within the limits. These limits were noted and marked on the sliding bar in further experimental works.

\section{Motionvelocities of sliding bar and crank} wheel

The tractor engine was operated at 1500 RPM and at this particular point PTO shaft rotates at 380 RPM and was measured using a mechanical tachometer.

The calculated velocities of sliding bar and crank wheel were given in Table 2. It was observed that the linear speed of sliding bar increased with increase of stroke length. The linear speeds of sliding bar for 20, 40 and 60 $\mathrm{mm}$ stroke lengths were observed to be 0.25 , 0.51 and $0.76 \mathrm{~m} \mathrm{~s}^{-1}$, respectively. The crank wheel peripheral and angular velocities were remained constant. The peripheral and angular velocity of crank wheel were $4.97 \mathrm{~m} \mathrm{~s}^{-1}$ and $39.77 \mathrm{rad} \mathrm{s}^{-1}$, respectively.

\section{Torque and force delivered to oscillating bar}

The torque delivered by the PTO shaft was $342.26 \mathrm{~N}-\mathrm{m}$. The crank wheel rotates at the same rotational speed as that of PTO speed, since the PTO shaft was connected to the crank wheel shaft directly. As per the design considerations, no reduction of power from the PTO shaft to crank wheel shaft was set.

The power delivered from the PTO shaft to the crank wheel through the shaft was taken as $13.62 \mathrm{~kW}$. So, the power delivered to the slider crank remains same $(13.62 \mathrm{~kW})$ since, there was no power reduction gear box. The revolutions of the crank wheel were observed as $380 \mathrm{rpm}$. The torque delivered by the crank wheel to the sliding bar was calculated using the equation

$$
\begin{aligned}
& T_{S C}=\frac{P_{S C} \times 60}{2 \pi N_{S C}} \\
& T_{S C}=\frac{13.62 \times 1000 \times 60}{2 \pi \times 380}
\end{aligned}
$$

$T_{S C}=342.26 \mathrm{~N}-\mathrm{m}$

The torque transmitted by crank wheel was calculated as $342.26 \mathrm{~N}-\mathrm{m}$.

The force acting on the crank wheel $=$ Torque on crank wheel / radius of crank wheel $=342.26 / 0.125=2738.08 \mathrm{~N}$.

The soil cutting force encountered by the machine was calculated taking the soil cutting resistance (0.5 $\mathrm{kgf} \mathrm{cm}^{-2}$ Mahilang et al., 2017) and effective soil cutting cross sectional area by the tool.

The effective cutting cross sectional area of soil by the individual tool when oscillating bar moves $6 \mathrm{~cm}$ length was $13.5 \mathrm{~cm}$ and depth of soil cutting was considered as $5 \mathrm{~cm}$.

The cutting force of soil acting on each tool $=$ $13.5 \times 5 \times 0.5=33.75 \mathrm{~kg}$

The total cutting force acting on six number of tools $=33.75 \times 9.8 \times 6=1984.5 \mathrm{~N}$ 
The weight of the sliding bar $\left(\mathrm{m}_{\mathrm{t}}\right)$ including acceleration due to gravity as $\left(9.81 \mathrm{~m} \mathrm{~s}^{-2}\right)$. The normal force $(\mathrm{N})$ of the sliding bar was calculated using equation

$F_{N}=m_{t} g$

$F_{N}=30 \times 9.81$

$F_{N}=294.3 \mathrm{~N}$

The oscillating bar oscillates sideways on Uchannel steel frame with the force of connecting rod. The coefficient of static friction for steel on steel was taken as 0.74 and normal force of the oscillating bar was $294.3 \mathrm{~N}$.

$F_{S}=\mu F_{N}$ working tools was calculated as $30 \mathrm{~kg}$ and $F_{s}=0.74 \times 294.3=217.78 \mathrm{~N}$

Now, total force acting on the sliding bar

$$
\begin{aligned}
& F=F_{C}+F_{S} \\
& F=1984.5+217.78 \\
& F=2202.28 \mathrm{~N}
\end{aligned}
$$

As per the soil resistance point of view, the total force $(2202.8 \mathrm{~N})$ acting on the sliding bar through soil cutting action found to be less than the force $(2738.08 \mathrm{~N})$ exerted by the crank wheel to the sliding bar. Hence, the design was satisfactory with the set parameters.

Table 1 Different stroke lengths for different crank positions

\begin{tabular}{|c|c|c|c|}
\hline $\begin{array}{c}\text { Clearance, } \mathbf{C}, \\
\mathbf{m m}\end{array}$ & $\begin{array}{c}\text { Crank radius, } \mathbf{r}, \\
\mathbf{m m}\end{array}$ & $\begin{array}{c}\text { Connecting rod } \\
\text { length, } \mathbf{L c}, \mathbf{m m}\end{array}$ & $\begin{array}{c}\text { Stroke Length, } \mathbf{m m} \\
\mathbf{S}=\mathbf{S e}-\mathbf{S f}\end{array}$ \\
\hline $\mathbf{2 5}$ & 10 & 700 & 20 \\
\hline $\mathbf{2 5}$ & 20 & 700 & 40 \\
\hline $\mathbf{2 5}$ & 30 & 700 & 60 \\
\hline $\mathbf{2 5}$ & 40 & 700 & 80 \\
\hline $\mathbf{2 5}$ & 50 & 700 & 100 \\
\hline
\end{tabular}

Table.2 Motions of sliding bar and crank wheel

\begin{tabular}{|c|c|c|c|}
\hline $\begin{array}{c}\text { Stroke } \\
\text { Length, mm }\end{array}$ & $\begin{array}{c}\text { Linear speed of } \\
\text { sliding bar, } \\
\mathbf{m ~ s}^{-\mathbf{1}}\end{array}$ & $\begin{array}{c}\text { Crank wheel } \\
\text { peripheral velocity, } \\
\mathbf{m ~ s}^{-\mathbf{1}}\end{array}$ & $\begin{array}{c}\text { Crank wheel } \\
\text { angular velocity, } \\
\text { rad s }^{-1}\end{array}$ \\
\hline $\mathbf{2 0}$ & 0.25 & 4.97 & 39.77 \\
\hline $\mathbf{4 0}$ & 0.51 & & \\
\hline $\mathbf{6 0}$ & 0.76 & & \\
\hline
\end{tabular}


Fig.1 Geometry representation of slider crank mechanism

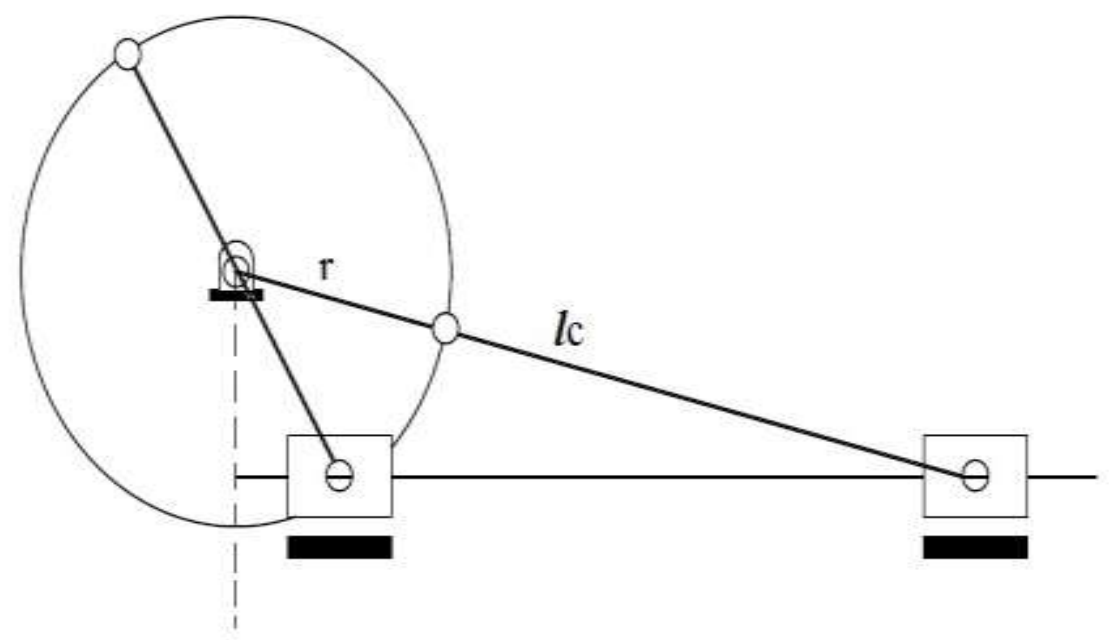

Fig.2 Isometric view of developed oscillating intercultural equipment
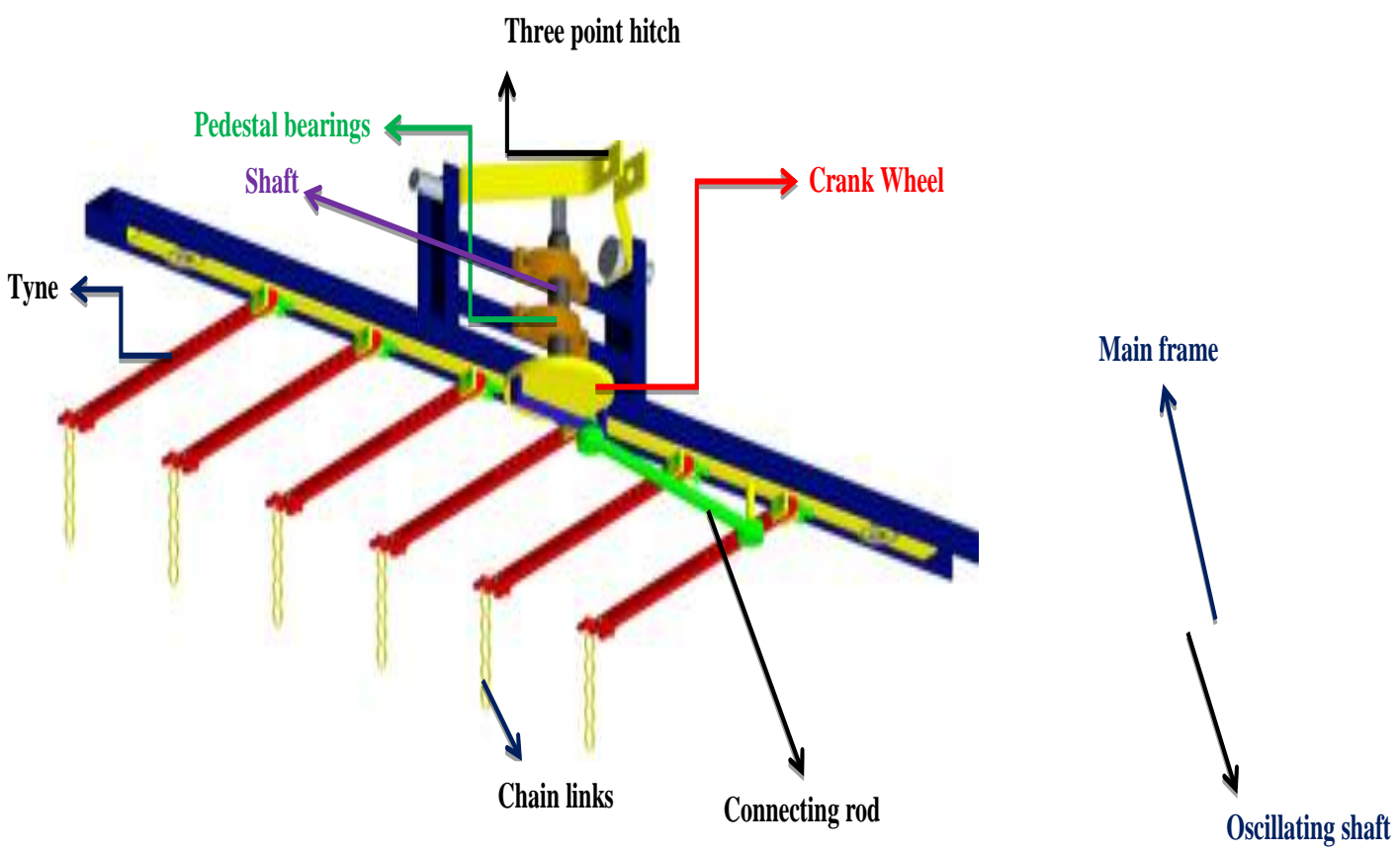
Fig.3 Effect of connecting rod length on stroke lengths at different crank positions

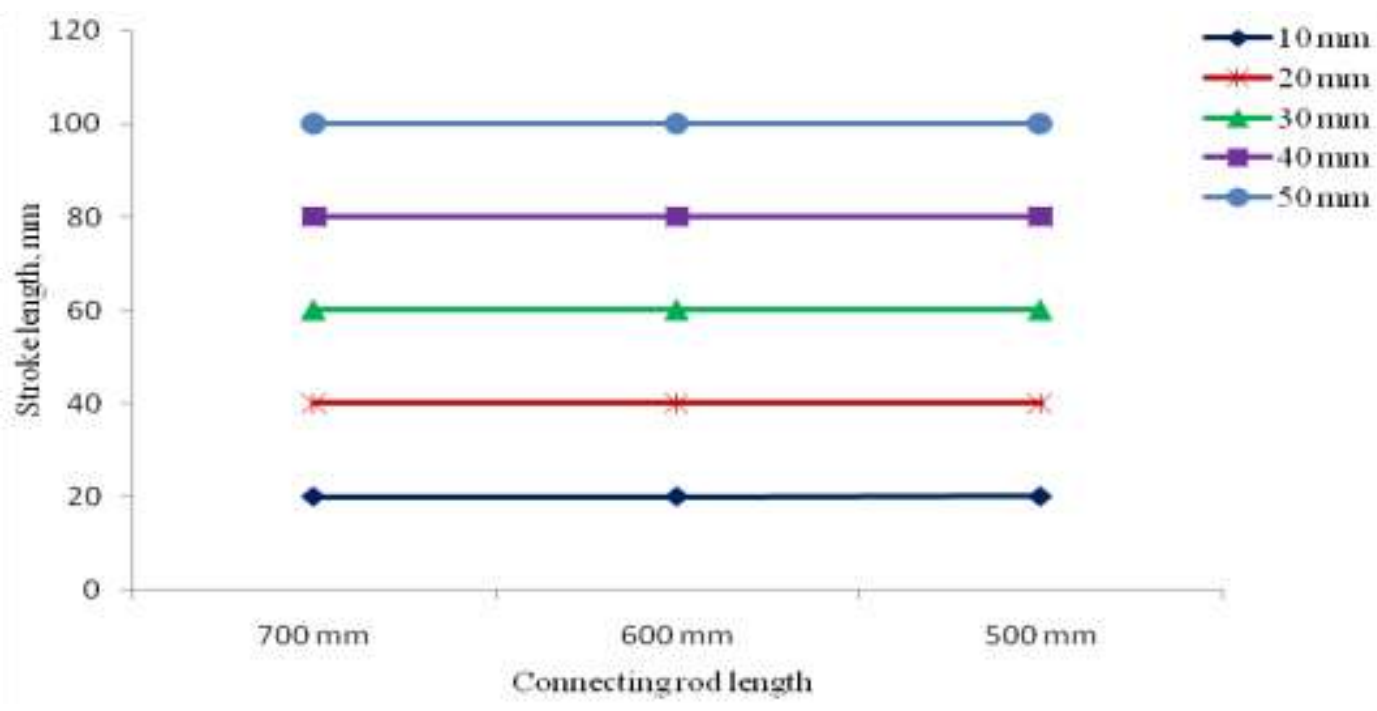

In conclusions the required stroke lengths selected for the weeding tool 60,40 and 20 $\mathrm{mm}$, could be obtained at crank radius of 30 , 20 and $10 \mathrm{~mm}$, respectively. The linear speeds of sliding bar for 20,40 and $60 \mathrm{~mm}$ stroke lengths were observed to be 0.25 , 0.51 and $0.76 \mathrm{~m} \mathrm{~s}^{-1}$, respectively. The peripheral and angular velocity of crank wheel were $4.97 \mathrm{~m} \mathrm{~s}^{-1}$ and $39.77 \mathrm{rad} \mathrm{s}^{-1}$, respectively. The force required to operate the slider bar in the mechanism was 2202.8 $\mathrm{N}$, whereas the force exerted by the crank wheel to the sliding bar was $2738.08 \mathrm{~N}$. Hence, the design was satisfactory.

\section{References}

Anonymous. 2018. International Rice Research Institute. http://ricestat.irri.org:8080/wrs.

Celik, A. 2006. Design and operating characteristics of a push type cutter bar mower. Canadian Biosystems
Engineering. 48: 223-227.

Ogunlowo, Q.O and Olaoye, J.O. 2017. Development and performance evaluation of a guided horizontal conveyor rice harvester. Agrosearch. 17(1): 66-88.

Rao, A.N. 2011. Integrated weed management in rice in India. https://www.researchgate.net/publica tion/216018976.

Savary, S., Castilla, N.P., Elazegui, F.A and Teng, P.S. 2005. Multiple effects of two drivers of agricultural change, labor shortage and water scarcity, on rice pest profiles in tropical Asia. Field Crops Research. 91: 263-271.

Singh, S., Singh, G., Singh, V. P. and Singh, A. P. 2005. Effect of establishment methods and weed management practices on weeds and rice in ricewheat cropping system. Indian Journal of Weed Science. 37: 51-57.

\section{How to cite this article:}

Anil Kumar, D., S. Joseph Reddy, B. Sanjeeva Reddy, L. Edukondalu and Srineevasa Rao, V. 2019. Design and Development of Oscillating Intercultural Equipment for Rice. Int.J.Curr.Microbiol.App.Sci. 8(01): 197-205. doi: https://doi.org/10.20546/ijcmas.2019.801.021 